\title{
EWSR1/FLI1 Fusion Protein
}

National Cancer Institute

\section{Source}

National Cancer Institute. EWSR1/FLI1 Fusion Protein. NCI Thesaurus. Code C99205.

A fusion protein encoded by the EWSR1/FLI1 fusion gene. This protein is comprised of the transactivation domain of the RNA-binding protein EWS fused to the C-terminal domain of the Friend leukemia integration 1 transcription factor protein, which includes the ETS DNA binding domain. 